\title{
Corrosion Behaviors of 5A06 Aluminum Alloy in Ethylene Glycol
}

\author{
Xiaoguang Zhang ${ }^{1}$, Xiang Liu ${ }^{2}$, Wenping Dong ${ }^{2}$, Gengkai Hu ${ }^{1}$, Pan Yi ${ }^{3}$, Yunhua Huang ${ }^{3}, K_{\text {Kui Xiao }}^{3, *}$ \\ ${ }^{1}$ School of Aerospace Engineering, Beijing Institute of Technology, No.5 South Zhongguancun Street, \\ Beijing 100081, China \\ ${ }^{2}$ National key laboratory of human factors engineering, China astronaut research and training center, \\ Beijing 100094, China \\ ${ }^{3}$ Institute of Advanced Materials and Technology, University of Science and Technology Beijing, \\ Beijing 100083, China \\ "E-mail: xiaokui@sina.com
}

doi:10.20964/2018.11.64

Received: 19 June 2018 / Accepted: 20 August 2018 / Published: 1 October 2018

As a coolant, ethylene glycol solution can influence the corrosion processes of 5A06 aluminum alloys that are used for aerospace applications. The corrosion behavior of 5A06 in contact with pure ethylene glycol was investigated via 3D confocal laser scanning microscopy, scanning electron microscopy and electrochemical impedance spectroscopy. The results demonstrated that pure ethylene glycol may suppress the anodic dissolution of the aluminum alloy, thus decreasing the corrosion rate in pure ethylene glycol. Furthermore, the protective effect of oxidation films was enhanced as the result of a layer of Al-alcohol products that formed above the oxidation films in ethylene glycol.

Keywords: Aluminum alloy, corrosion mechanisms, ethylene glycol, organic, EIS

\section{$\underline{\text { FULL TEXT }}$}

(C) 2018 The Authors. Published by ESG (www.electrochemsci.org). This article is an open access article distributed under the terms and conditions of the Creative Commons Attribution license (http://creativecommons.org/licenses/by/4.0/). 